\title{
Possibilidades Formativas do Cinema ${ }^{1}$
}

\author{
Rogério de Almeida ${ }^{2}$
}

${ }^{l}$ Este artigo apresenta resultados de pesquisa financiada pela FAPESP na modalidade Auxílio Regular. Trata-se de uma tradução modificada da publicação originalmente em inglês: ALMEIDA, Rogério de. "Formative Possibilities of Cinema". In: Ulla Carlsson; Sherri Hope Culver. (Org.). Media and Information Literacy and Intercultural Dialogue. Göteborg: Nordicom, 2013, p. 49-58. 2 Professor da Faculdade de Educação da Universidade de São Paulo (USP). Lidera o GEIFEC (Grupo de Estudos sobre Itinerários de Formação em Educação e Cultura) e coordena, junto com Marcos Ferreira Santos, o Lab_Arte (Laboratório Experimental de Arte-Educação \& Cultura). É bacharel em Letras (1997) e doutor em Educação (2005), ambos os títulos pela Universidade de São Paulo (USP). 


\section{Resumo}

Possibilidades Formativas do Cinema parte da concepção de dois usos distintos tanto do cinema quanto da educação: um voltado para a exposição do mundo, com a finalidade pedagógica do reconhecimento e validação de sua representação, e um outro uso direcionado para a problematização do mundo, tanto o que se desenha na tela do cinema quanto o que se apresenta como real. O objetivo é explorar as possibilidades pedagógicas do cinema que problematiza o mundo e afirma o real, mesmo diante de uma realidade desagradável.

Palavras-chave: cinema; educação; itinerários de formação; pedagogia da escolha.

\section{Abstract}

"Formative possibilities of cinema" spawns from the concept of two distinct uses of cinema and of education: one directed towards exposing the world, with the pedagogical purpose of recognizing and validating its representation, and the other focused on problematizing the world, taking into account what is pictured on the screen as well as what is presented as real. The goal is to explore the pedagogical possibilities of a cinema that questions the world and affirms what's real, even before an unpleasant reality.

Keywords: cinema; education; processes of formation; pedagogy of choice. 
O cineasta chileno Raúl Ruiz (2000, p. 86) faz uma interessante provocação ao imaginar como seria se se propusesse, nos primórdios do cinema, um filme sobre a volta ao mundo em oitenta dias. Os irmãos Lumière ligariam a câmera e percorreriam o mundo, filmando a viagem, enquanto Georges Méliès correria para seu estúdio e recriaria o mundo cenograficamente. Historicamente, poderiam ser traçados dois caminhos como propostas diferentes de cinema: o realismo e a ilusão, por exemplo; mas também outras dicotomias, como a crítica e o mercado, a arte e a indústria, o pensamento e a diversão e assim sucessivamente, num exercício tão rico quanto a arbitrariedade das divisões, pois efetivamente nada nos autoriza a reduzir a multiplicidade de usos e possibilidades da cinematografia a qualquer par dicotômico.

Não nos obstando essa ressalva, pretendo, ainda que provisoriamente, insistir em dois usos distintos que podemos fazer da cinematografia em estrita relação com a formação humana, sem, no entanto, reduzir o cinema a uma função pedagógica. Esses usos se dividiriam em um cinema que se propõe a uma visão naturalizada de mundo em oposição a um outro que visaria à sua problematização. Dito assim, parece que estamos diante de mais uma redução simplista e, de fato, seria, se a finalidade fosse dar conta do cinema, mas a intenção aqui é outra: lançar mão desse exercício, dessa suposição ou pressuposto como uma heurística possível para se compreender a potencialidade formativa do cinema. Assim, depois de utilizado este andaime argumentativo, deveremos nos livrar dele, restituindo o cinema à multiplicidade que o caracteriza, como, aliás, a toda arte.

O mesmo recurso pode ser utilizado a respeito da educação, em relação à qual subsistiriam duas intenções pedagógicas, uma voltada para a exposição do mundo, mais especificamente de um mundo que se quer reconhecer, e outra direcionada para a problematização, para o questionamento desse mundo apresentado.

De maneira mais filosófica, há de um lado a crença de que há algum princípio que norteia a existência e, de outro, a desconfiança, não só de um ou outro princípio, mas da existência mesmo de princípios. Assim, a educação religiosa 
elegerá Deus como o princípio, ou seja, o dado fora da existência que se torna o autor da existência e, também, seu juiz. Como responsável pelo jogo da existência, a ele se atribuem as regras, muitas das quais foram historicamente reveladas, enquanto outras são ou podem ser deduzidas, permanecendo o mistério para tudo o que não aparece como regra.

Já a educação científica crê em outro princípio, atestado pela verificabilidade de seus métodos, e que pode ser expresso de modo amplo e um tanto caricatural, como natureza, ou physis, ou ainda uma espécie de força que, precedendo a existência, atuasse para o seu início e permanecesse continuamente se renovando. De modo mais comum, é o que se chama "leis da natureza", ou seja, a ideia de que a realidade das coisas é operada por forças que the são alheias e determinantes. A natureza seria, então, o princípio que faz com que as árvores cresçam, as nuvens formem-se e as espécies evoluam. Educar para a ciência presume conhecer e adotar as condições para que determinado conhecimento seja aceito como válido, pois foi cientificamente comprovado. O que não passa pela peneira do cientificismo, ou é falso ou é conhecimento menor (empírico, prático, supersticioso, do senso comum etc.).

Por meio da eleição de um princípio organizador do real cria-se a ilusão de que há uma verdade, um princípio, uma realidade, um fato, enfim, um absoluto que possa servir de referência de mundo, em relação ao qual usaríamos a linguagem para representar. Dessa forma, fabrica-se um hiato entre o que se diz, o que se pensa, o que se cria e o mundo "de fato", mundo "verdadeiro". Fabrica-se uma realidade, uma verdade, que passa a funcionar como princípio, em relação ao qual se pode avaliar as diversas linguagens e suas formulações, suas criações.

Desse modo, mais que uma pedagogia, há usos pedagógicos de materiais e discursos dos mais distintos com essa finalidade de limitar a linguagem à expressão de uma só realidade, uma só verdade, um só mundo. No caso do cinema, que não tem a priori finalidade pedagógica ou educativa (salvo raras e dispensáveis exceções), há um uso pedagógico que consiste em tomá-lo como discurso ou representação da realidade. Por essa estratégia, usam-se filmes ou 
trechos de filmes como recurso auxiliar, exposição de um conhecimento que se quer comunicar. Nesse sentido, dissemina-se uma ideia de que é didático tudo o que auxilia na comunicação, na transmissão de um certo conhecimento, tido previamente como verdadeiro porque é verdadeiro, ou seja, porque é assim afirmado pela ciência, pela ideologia, pelo discurso escolar dominante. No caso específico do espaço escolar, há ainda o uso deplorável de filmes como substituto de aula, atividade diversionista sem compromisso com o trabalho reflexivo e formativo (Almeida \& Ferreira Santos, 2014).

Voltando à questão inicial, podemos dizer de modo bastante amplo que há duas formas de conceber a realidade, a existência ou o mundo: uma que visa à sua naturalização, ou seja, que afirma um princípio, uma verdade, um conjunto mais ou menos estável de conhecimentos, crenças, valores e modos de julgar; e uma outra forma que problematiza qualquer concepção naturalista, homogênea, dogmática, optando pelo acaso em vez do princípio, pelo vazio em vez do absoluto, pela multiplicidade das interpretações em vez da versão única.

Dito de outro modo, há duas forças em conflito: uma que busca a estabilização do mundo e outra que o admite instável; uma que crê no progresso e outra que descrê da história; uma que contabiliza os grandes feitos da humanidade, ainda que com muitos sacrifícios e outra que desdenha da grandeza humana, pela impossibilidade de fundamentação dos valores; uma que elege a razão como possibilidade de acesso à verdade e outra que desconfia da razão por sua incapacidade de aceitar seus limites; uma que fabrica utopias e outra que afirma a crueza da existência; enfim, uma que se apodera muito naturalmente do mundo e outra que o estranha constantemente.

Essas duas forças, essas duas maneiras de conceber o mundo poderiam ser aplicadas à filosofia e não seria difícil mapear os filósofos naturalistas e os artificialistas (Almeida, 2012). Poderíamos mesmo tratar de duas estéticas, de duas éticas ou de duas mitologias, porque o que está no cerne da questão são os pressupostos, sejam eles explicitados ou não, que norteiam nossos modos de viver, de pensar e de agir, nossas visões de mundo, nossas perspectivas 
existenciais. Para o presente estudo, ateremo-nos ao modo como essas duas perspectivas incidem nas obras cinematográficas e nos usos pedagógicos do cinema, buscando a compreensão dos seus aspectos formativos.

\section{Tela, janela e espelho}

Transformar o cinema em atividade de lazer, passatempo, distração é uma forma de anestesiar o espectador, tirá-lo do seu cotidiano sem necessariamente instigar a reflexão ou o pensamento, sem the possibilitar questionar o próprio cotidiano em que vive. $E$ isso porque compactua, ideológica e esteticamente, com o reforço de dadas convenções, principalmente as produtivistas, que medem o homem pelos resultados de seu trabalho, que entendem formação de maneira instrumental e veiculada à profissão e compreendem a fruição estética propiciada pelas artes como uma atividade ligada ao ócio e à distinção de classe.

Poderíamos, nesse sentido, arrolar inúmeros exemplos, mas basta ficarmos com os filmes hollywoodianos de aventura, cujo imaginário heroico é bastante disseminado. Reconhecem-se o bem e o mal, o herói e o vilão, a motivação para o combate e o final apoteótico, com a grande luta seguida da recompensa, quase sempre os braços de uma mulher. É mais que um clichê, é todo um gênero.

Mas meu interesse não é criticar, condenar ou diminuir o cinema dito comercial, atrelado à indústria cultural, mas pontuar que há diversos interesses em jogo na exploração do cinema como produto de consumo; entre eles, o de obstruir ou obnubilar seu papel formativo. Como distração ou passatempo, o cinema se converte numa espécie de intervalo, de afrouxamento, de descanso entre atividades sérias, importantes, significativas. Subtrai-se, assim, sua possibilidade de pensar, inclusive de pensar contra si mesmo. Transformado em ilusão, como se sua função fosse apreender ou representar o real - tarefa que será sempre falha, trate-se de cinema, fotografia, literatura, ciência ou filosofia -, é-lhe vedado o exercício do questionamento, da desestabilização, do estranhamento, da contestação. 
É necessário, então, que os filósofos tomem a palavra e façam a defesa do cinema:

Os grandes autores de cinema nos pareceram confrontáveis não apenas com pintores, arquitetos, músicos, mas também com pensadores. Eles pensam com imagens-movimento e com imagens-tempo, em vez de conceitos. A enorme proporção de nulidade na produção cinematográfica não constitui uma objeção: ela não é pior que em outros setores, embora tenha consequências econômicas e industriais incomparáveis. Os grandes autores de cinema são, assim, apenas mais vulneráveis; é infinitamente mais fácil impedi-los de realizar sua obra (Deleuze, 1985, p. 8).

Deleuze $(1985,1990)$ dedica duas obras à defesa do cinema como pensamento, trabalhando com os conceitos de imagem-movimento e imagemtempo. A montagem no cinema clássico seria a responsável, por meio do sequenciamento dos planos, por criar a sensação de movimento, de imagemmovimento. Por meio de outro modus operandi, o cinema moderno rompe com a linearidade temporal, evidenciando a manipulação do tempo, engendrando a imagem-tempo.

O cinema torna-se, nesta perspectiva, consciente da produção de imagensmovimento e imagens-tempo que opera. Está apto, portanto, a pensar sobre si mesmo e contra si mesmo, consciente de que não é a representação do mundo, mas a proposição de mundos, como se expusesse, além de suas imagens, sua própria linguagem, ou seja, as condições para sua existência.

Como não nos lembrarmos de Janela Indiscreta, de Alfred Hitchcock? A câmera, depois de percorrer o pátio que servirá de cenário, entra pela janela de James Stewart, mostra a gota de suor em sua testa, seu pijama, a perna engessada, uma máquina fotográfica, fotos de carro, pilhas de revista, enfim, toda a situação nos é dada visualmente. Sabemos que é manhã, que está calor, que o fotógrafo está imobilizado devido a um acidente de carro... O filme nos provoca com a ideia, até certo ponto moralmente censurável - a cremos nas discussões postas na tela -, de que somos, quando assistimos a um filme, tão voyeurs, curiosos ou xeretas quanto o protagonista, que insiste em dotar de significado as cenas que aprecia de sua janela. O que ele sabe da vizinha solitária? Como julgar 
a dançarina apenas com as imagens entrevistas pelas janelas? Como inferir, sem testemunhar, apenas por indícios, que o marido assassinou sua mulher? Compactuamos com seu olhar, ainda que possamos duvidar de suas elucubrações, numa clara metáfora de que o cinema é como uma janela, desde que não se creia muito apressadamente de que mostra o que é real, portanto verdadeiro. Não são fatos que vemos pela janela, mas interpretações, possibilidades de compreensão, hipóteses. Estamos continuamente complementando as imagens com nosso repertório pessoal. É esta a dinâmica do imaginário: as imagens sempre dizem muito pouco, somos nós que complementamos suas imperfeições, suas lacunas, sua falta de clareza, a despeito de toda nitidez ${ }^{3}$. Há aqui uma atividade cognitiva constante: nas inferências, na construção da história, na avaliação das hipóteses, no julgamento das condutas, nas dúvidas levantadas, nas possibilidades de desfecho. De certo modo, a forma do filme contribui na formação do espectador ao propiciar formas diferentes de observar uma mesma realidade.

Outro exemplo dessa consciência que o cinema tem, ou parece ter, sobre seu poder de diálogo com a vigília e o sonho, o fato e a versão, o real e a ilusão, o que aconteceu e o que poderia ter acontecido aparece na obra Raros Sonhos Flutuantes (1990), de Eizo Sugawa. O filme é um tanto desconhecido e o cineasta pouco apreciado no Japão, o que dificulta que o filme circule (nunca foi lançado em cópia digital), mas sua riqueza é ímpar e merece ser explorada, razão pela qual parafraseio o filme antes de comentá-lo.

Shuji, um homem de meia idade, está em um hospital, com a perna imobilizada após um acidente e, devido à falta de leitos, vê-se obrigado a compartilhar o quarto com uma paciente de nome Mutsuko. Separados por uma tela de pano, imóveis, empreendem uma conversa noturna sobre poesia. Ela provoca a imaginação de Shuji, que aceita o jogo e passa a descrever como seria o amor

\footnotetext{
${ }^{3}$ Nesse sentido, conferir o estudo sobre Janela Indiscreta que Bordwell (1996) realiza para ilustrar as múltiplas inferências que o espectador faz ao longo do filme na construção de sua história, a partir das informações disseminadas pelo argumento e pelo estilo.
} 
entre ambos, numa atmosfera bastante erótica. No auge do diálogo, a câmera afasta-se até a janela (outra tela) e vemos a neve batendo contra o vidro, numa insinuação metafórica da relação do casal.

Na manhã seguinte, a tela é retirada por um breve instante, o suficiente para Shuji perceber que Mutsuko é idosa. Passam-se alguns meses, Shuji está trabalhando num escritório da empresa destinado à reabilitação de seus funcionários, quando Mutsuko telefona e marca um encontro. Ela aparece saindo do metrô, atrás de uma proteção de vidro (outra tela), com a imagem dele refletida sobre a dela, que aparenta ter quarenta anos. Ficamos sabendo, então, que ela tem sessenta e sete anos e que, depois de um sono prolongado de dez dias, começou a rejuvenescer. Os dois vão a um hotel e concretizam o amor outrora imaginado. A câmera abandona o casal e fixa-se na janela do hotel (novamente a tela). Assistimos simultaneamente a imagem do lado de fora e de dentro: o sexo refletido no vidro com o céu de fundo.

Meses depois, Mutsuko retorna com aparência anda mais jovem; Shuji cogita abandonar seu trabalho, sua família (esposa e filho), para viver com ela. Desta vez, sua aparição dá-se ao crepúsculo, debaixo de chuva. Ela está molhada e é vista por Shuji atrás de uma porta de vidro (sempre a tela). A luz de dentro reflete a imagem dele no vidro. Antes de abrir a porta, ele apaga a luz, para vê-la melhor, numa possível referência à escuridão das salas de cinema, necessária para maior nitidez das imagens projetadas. Numa passagem belíssima, ela está prestes a se entregar a ele como se fosse a primeira vez. Sente-se como uma virgem e the diz que o corpo comanda as emoções. De nada the valem os sessenta e sete anos de experiência, o corpo a faz se sentir como uma garota, a emoção sobrepõe-se à razão.

Depois de novo hiato de tempo, Shuji encontra Mutsuko adolescente, com saia curta, rebelde, volúvel, agindo de maneira intempestiva, portando uma arma, mas absolutamente consciente de sua situação e de seu amor. Descobrimos, então, após Shuji ser denunciado à polícia por pedofilia, que o denunciante, um homem de meia idade, é filho de Mutsuko e está à procura dela para resolver questões de 
herança. Obviamente, ele não reconhece a mãe no corpo adolescente, embora intua que ela tenha alguma relação com o caso. $O$ fato é que o contraste se evidencia: embora filho, ele aparenta ter a idade de pai dela.

Shuji é preso e julgado pelo crime de pedofilia, levando escândalo para a família, que não o compreende. O final do filme dá-se com a última aparição de Mutsuko, uma criança aparentando ter seis, sete anos, mas com a lucidez e raciocínio de sua idade de sessenta e sete. Shuji Ihe pergunta como conseguiu comprar suas roupas sozinha. Ela responde que as comprou quando era adolescente e pede que tomem banho juntos. Depois da conversa adulta entre o homem e a menina na banheira, a última cena mostra Shuji caminhando por uma calçada, com Mutsuko em seu colo. Eles se despedem, ela reafirma que é necessário que o façam e parte caminhando sozinha no meio da multidão. $A$ câmera, assim como Shuji, fica parada e nós a vemos cada vez mais distante, perdendo-se na multidão, assim como perdemos a memória de nossos sonhos no fluxo da vigília.

Mutsuko é como uma imagem cinematográfica, aparece sempre mediada pela tela, mas no filme a tela se rompe e ela realiza os desejos de Shuji. De certa forma, o cinema funciona como os sonhos flutuantes. As imagens pairam sobre a tela e, por instantes, aquele mundo é como se fosse real, ainda que depois tenhamos de nos despedir daquelas imagens, como Shuji se despede de Mutsuko. Entretanto, não estamos perto do fim, mas do início. O final do filme é como um retorno a nós mesmos, aos nossos sonhos, aos nossos primórdios, daí a imagem forte da criança, para quem todas as possibilidades de realização estão abertas. O cinema, assim como os sonhos e os desejos, renova-nos, não num sentido otimista, como se pudéssemos ser novamente novos, mas no sentido de nos colocar em contato com nossas mais íntimas obsessões, nossos medos e angústias, nossos desejos inconfessos ou mesmo raros ${ }^{4}$.

\footnotetext{
${ }^{4}$ Edgar Morin (2001) dedica um longo estudo sobre o imaginário cinematográfico e sua relação com a magia e o mundo onírico, evidenciando como a subjetividade se projeta nas e se identifica com as imagens da tela.
} 
Para o filósofo francês Clément Rosset (2010, p. 14), um filme é como um longo sonho, enquanto o sonho é como uma "micro-metragem", ambos possuem roteiro, fotografia, diretor e produtor, mas enquanto o cinema interessa a um dado público, o sonho só interessa a quem o sonha. Raros Sonhos Flutuantes não tenta em momento algum nos convencer de que Mutsuko é real. Por isso, em momento algum aventa a possibilidade de que seja sonho, alucinação, devaneio ou apele para uma explicação pseudocientífica. Aceitamos desde logo a dupla realidade da imagem (Aumont, 1993). Sabemos que ela é superfície, mera projeção, mas simultaneamente aceitamos o que é figurado por ela. Sabemos que é a imagem de Mutsuko, e não a própria Mutsuko, que estamos vendo. Acreditamos em seu rejuvenescimento, não porque seja realmente ou racionalmente possível, mas porque o cinema, pela sua proximidade do real, propõe-nos sempre uma outra realidade, ou ainda, uma outra cena da realidade (Rosset, 2010, p. 56). Assim, acreditamos no rejuvenescimento de Mutsuko porque Shuji acredita, porque a vemos rejuvenescida, porque é possível crer na imagem projetada, já que sabemos que ela é imagem e não realidade, ou melhor, que é justo uma imagem e não uma imagem justa, para relembrarmos de Godard (apud Rosset, 1985).

Por fim, sobre este filme, é preciso insistir uma última vez no fato de que a aparição de Mutsuko se dá sempre mediada por uma superfície, uma tela, um vidro. Inicialmente, a tela de pano que separa as camas no hospital. Não estamos nós também separados da realidade cinematográfica justamente pela tela sobre a qual se projeta o filme? Não temos a impressão de que podemos saltar para dentro da tela, ou melhor, de que o personagem, assim como ocorre em A Rosa Púrpura do Cairo (1985), de Woody Allen, vai saltar para nossa realidade? Nesse sentido, a recente tecnologia das três dimensões, o 3D, não explora, além da ilusão mais realista de profundidade, justamente a imagem que salta para fora da tela?

De volta ao filme em análise, Mutsuko é mostrada ao menos outras três vezes atrás de um vidro ou projetada sobre a superfície transparente de um vidro, como se fôssemos constantemente alertados de que se trata de uma imagem, da 
projeção de uma imagem, do reflexo (poderia ter escrito reflexão) de uma imagem. Estaríamos como que sonhando? Sim, desde que, durante o sonho, estivéssemos conscientes de que se tratava de sonho, tese proposta pelo filme La science des rêves (2006), de Michel Gondry, que obviamente transfere essa zona de indefinição do protagonista para nossa realidade, de modo que durante o filme também deixamos de saber o que é sonho e o que é realidade, embora não deixemos de saber que é só um filme.

Ainda com Raros Sonhos Flutuantes, Mutsuko também aparece mediada pela tela de uma máquina fotográfica, como uma imagem congelada que pode ser revista, como uma evocação da realidade ocorrida e para sempre perdida, pois presa a um passado que não pode ser revivido como presente, mas relembrado como imagem ou por meio da imagem.

Outra cena memorável é quando Shuji entra em casa discutindo com sua esposa. Observamos os dois aproximando-se, até que a mulher atira o sapato em direção à câmera, ou seja, em nossa direção, mas o sapato atinge o espelho, que se quebra em pedaços. O espelho partido e o reflexo fragmentado do casal coincidem com o momento em que descobrimos que a imagem que víamos não era real, mas o reflexo de um espelho. Portanto, se a tela do cinema pode ser transparente como vidro, isto é, uma janela que nos abre outra paisagem, também pode ser opaca como espelho, no qual nos vemos refletidos (ou projetados), mas com a tranquilidade de nos sabermos a salvo, comodamente sentados na poltrona. É o que defende Clément Rosset (2010, p. 26) quando diz que no cinema somos voyeurs tranquilos (enquanto no mundo real o voyeur está sempre angustiado): vemos tudo sem sermos surpreendidos por ninguém.

Esses exemplos retomam o que foi dito anteriormente, no início desta seção, sobre o caráter da consciência que o cinema tem de si como arte, como linguagem e como possibilidade. E essa questão é importante para compreendermos o caráter formativo do cinema, como pode constituir um itinerário de formação. 


\section{Itinerários de formação}

Todo processo de compreensão é um exercício de tradução (Steiner, 2005). Assim, "leitura e interpretação são, em última análise, 'tradução' que dá vida, que empresta vida à obra gelada, morta. Através da 'tradução', a minha própria linguagem torna-se uma com a do criador" (Durand, 1998, p. 252).

Isso significa que a relação do espectador com o filme é ativa, o cineasta elabora a narrativa, mas é o espectador que recompõe a história, que a traduz. Compreender uma obra, interpretá-la, presume uma atividade formativa, não só pela dimensão cognitiva, de pensamento, mas também por ativar a sensibilidade, a imaginação, isto é, a capacidade de dotar de sentidos a experiência vivida.

Para Deleuze (1990), o olhar cinematográfico transforma o real em imaginário ao mesmo tempo em que se torna real para nos devolver realidade. De maneira mais simples, uma ideia parecida é desenvolvida por Clément Rosset (1985), que compreende a impossibilidade de o cinema fixar, apreender o real, embora possa projetar olhares sobre o real, ou seja, o cinema compõe sua própria realidade, uma outra realidade, que não é muito distante da nossa, mas que dialoga com ela, para questioná-la, desestabilizá-la, problematizá-la, desnaturalizá-la ou mesmo torná-la menos séria, menos importante, menos pesada.

Nem todo cinema, assim como nem todo espectador, encaixa-se nisso, mas a exigência de universalidade não é aqui necessária; mais interessante é pensar a questão das possibilidades formativas, pois não há um único itinerário de formação, mas caminhos plurais que precisam ser descobertos pela própria pessoa que busca sua autoformação. Não se trata de traçar uma receita para uma formação homogeneizante do homem. O que se quer é enfatizar a diferença antropológica, as possibilidades plurais dos modos de existir no mundo (Almeida, 2011).

Como afirma Fresquet (2013, p. 25), o cinema intensifica as invenções de mundo, perturba a ordem dada e possibilita uma leitura ao mesmo tempo intelectual e sensível dos filmes. 
O cinema, também como um outro, alarga nosso conhecimento do mundo, do tempo e nós mesmos. A possibilidade de identificar essa relação entre mim e o outro, mediada pela câmera, constitui uma mola para ativar a tensão entre dois estados cuja potência pedagógica o cinema movimenta com especial competência: crer e duvidar. Transitar entre esses dois polos que paralelamente nos aproximam de certa materialidade do real para o infinito do imaginário exercita a inventividade de ensinantes e aprendentes em dois gestos fundadores da educação: descobrir e inventar o mundo (Frequet, 2013, p. 123).

Dessa forma, retornamos à questão inicial de uma divisão, tanto do cinema quanto da pedagogia, em relação às suas possibilidades. Há no cinema e nos itinerários de formação, ou seja, nos processos interpretativos e assimilativos que perfazem o longo caminho de (auto)formação humana (Ferreira Santos \& Almeida, 2012, p. 142 a 145), a possibilidade de escapar dos discursos pré-estabelecidos sobre o sentido do mundo, do real, do homem, da vida, da sexualidade, da ética, etc. Se há um cinema que apresenta o mundo projetado como equivalente ao mundo real, há em contrapartida um cinema que é apenas uma cena possível do real, uma outra realidade ou uma outra cena desta mesma realidade. O mesmo ocorrendo com a pedagogia, que oscilará entre a tentativa de restringir seus ensinamentos a uma única versão (a versão pretensamente verdadeira, subentende-se) e a recusa de admitir que qualquer linguagem possa dar conta da realidade a que se refere, optando pelas interpretações possíveis, pela desconfiança permanente de todos os discursos, inclusive os cinematográficos, que oscilam entre a opacidade e a transparência (Xavier, 2005).

Nesse sentido, Rosset (1985) diferencia o cinema entre os que buscam uma imagem exata do real e os que se satisfazem apenas com mais uma imagem do real. Os primeiros creem na possibilidade de apreender cinematograficamente $o$ real, ainda que só realizem discursos pré-concebidos do que seja o real (representação); neste caso, a imagem equivaleria ao significado pressuposto do que é o real, uma interpretação, um discurso sobre o real (p. 57). Quando o cinema se propõe a mostrar apenas uma imagem, essa imagem não se quer totalidade, mas uma imagem a mais, uma proposição possível de mundo (e não a representação do mundo possível), isto é, um cinema que sabe não ser mais do 
que imagens. É um cinema que não almeja representar o real, mas tem sua realidade na fragmentação e reordenação de imagens do real. A realidade projetada na tela só se torna real à medida que o espectador aceita o jogo da fruição, ou seja, admite que se trata apenas de uma imagem, mas que pode ser olhada como se fosse real. Assim, quanto mais se dilui na realidade do filme, mais distante está da própria realidade. E é esse distanciamento, essa experiência, essa passagem por uma outra realidade que possibilita um ganho no retorno à realidade aqui. As luzes se acendem, os créditos sobem, podemos refletir sobre o que acabamos de assistir (buscar um benefício intelectual da experiência fílmica), podemos refletir sobre como nos sentimos em relação ao filme (buscar um benefício psicológico), mas podemos simplesmente tentar esquecer o que vimos (como se esquece um sonho ao acordar) e retomar as tarefas do cotidiano. Em qualquer uma das reações, saímos do filme diferentes do que entramos, mais ou menos alegres, aborrecidos, pensativos, incomodados, enfim, saímos com a necessidade de nos situarmos outra vez no mundo. E é esse exercício de nos situarmos constantemente e outra vez no mundo, porque um filme nos desorientou, nos des-situou, que constitui o caráter formativo do cinema. A equação entre a somatória desses momentos, a subtração de outros tantos, tudo multiplicado pelos discursos que nos atravessam, é que resultará nos nossos itinerários de (auto)formação.

Não nos esqueçamos das formas simbólicas às quais se refere Cassirer (1994, p. 234): "Tal como todas as outras formas simbólicas [filosofia, ciência, religião], a arte não é uma simples reprodução de uma realidade dada, pronta. É um dos meios que levam a uma visão objetiva das coisas e da vida humana. Não é uma imitação, mas uma descoberta da realidade".

Portanto, ao problematizar nosso olhar sobre o mundo, os outros e nós mesmos, o cinema, principalmente quando compreendido em sua faceta formativa, que é uma dentre outras possíveis, propicia um efeito pedagógico que a pedagogia da explicação e da transmissão ou comunicação de conhecimentos não logra atingir, de nos colocar diante de uma dada realidade e simultaneamente 
à distância. Gozamos e sofremos não o que a vida nos distribui, mas o que se projeta na tela. Participamos sem compromisso de outras vidas e realidades.

De modo pontual, podemos arrolar as seguintes possibilidades formativas do cinema:

- experiência estética: a relação com os filmes se dá por meio de sensações, somos afetados pelas imagens, aprendemos a fruir;

- imersão no imaginário: o filme opera uma mediação simbólica na relação com o mundo, com os outros e conosco mesmos;

- modelos de existência: o cinema nos põe em contato com arquétipos humanos, com os quais nos relacionamos por meio de identificação/projeção (Morin, 2001);

- formas de pensamento: embora o cinema narrativo de ficção não opere com conceitos, constitui-se como pensamento, pensa com imagens-movimento e imagens-tempo (Deleuze, 1985; 1990), ensinando modos plurais de pensar, além de ele próprio ser material para o pensamento.

Para concluir, é preciso admitir que provavelmente para muitos o cinema não seja nada disso e nem possa tanto, que sua sedução seja alienante, que seus interesses se reduzam a business, que seus temas cedam a apelações moralmente degradantes e que sua influência seja tão maligna quanto a da literatura novelesca para Dom Quixote e Madame Bovary. Ou seja, que o cinema é mais perigoso que educativo. Pode ser que sim, e é até provável que seja assim mesmo. Mas talvez essa interpretação não se aplique somente aos filmes, talvez se estenda a toda a realidade. E, então, se de fato for assim, teremos de fazer uma última divisão das pedagogias: as que têm por objetivo afirmar o real, mesmo no que têm de desagradável, e as que se contentam com a fantasia de um mundo melhor, ainda que pagando o preço da ilusão. 


\section{Referências Bibliográficas}

ALMEIDA, Rogério de. O Criador de Mitos: imaginário e educação em Fernando Pessoa. São Paulo: Educ, 2011.

"Artifício e Natureza: a multiplicidade dos modos de existência". In: PAGOTTO-EUZEBIO, Marcos Sidnei \& ALMEIDA, Rogério de (orgs.). Sobre a Ideia do Humano. São Paulo: Képos, 2012.

ALMEIDA, Rogério de; FERREIRA-SANTOS, Marcos (Orgs.). O cinema e as possibilidades do real. São Paulo: Képos, 2014.

AUMONT, Jacques. A Imagem. Campinas: Papirus, 1993.

BORDWELL, David. La narración en el cine de ficción. Barcelona, Buenos Aires, México: Paidós, 1996.

CASSIRER, Ernst. Ensaio sobre o Homem: introdução a uma filosofia da cultura humana. São Paulo: Martins Fontes, 1994.

DELEUZE, Gilles. Cinema: imagem-movimento. São Paulo: Brasiliense, 1985.

. Cinema: imagem-tempo. São Paulo: Brasiliense, 1990.

DURAND, Gilbert. Campos do Imaginário. Lisboa: Instituto Piaget, 1998.

FERREIRA-SANTOS, Marcos \& ALMEIDA, Rogério de. Aproximações ao Imaginário: bússola de investigação poética. São Paulo: Képos, 2012.

FRESQUET, Adriana. Cinema e Educação: reflexões e experiências com professores e estudantes de educação básica, dentro e "fora" da escola. Belo Horizonte: Autêntica, 2013.

MORIN, Edgar. El cine o el hombre imaginario. Barcelona/Buenos Aires/México: Paidós, 2001.

ROSSET, Clément. L'objet singulier. Paris: Minuit, 1985.

Reflexiones sobre Cine. Buenos Aires: El cuenco de Plata, 2010.

RUIZ, Raúl. Poética del Cine. Santiago/Chile: Editorial Sudamericana, 2000.

STEINER, George. Depois de Babel: questões de linguagem e tradução. Curitiba: Editora da UFPR, 2005. 
XAVIER, Ismail. O discurso cinematográfico: opacidade e transparência. São Paulo: Paz e Terra, 2005. 